\title{
Sol-Gel TiO 2 Thin Films Sensitized with the Mulberry Pigment Cyanidin
}

\author{
Emerson Henrique de Faria, Alex Lemes Marçal, Eduardo José Nassar,
}

Katia Jorge Ciuffi*, Paulo Sergio Calefi*

Universidade de Franca - UNIFRAN, Av. Dr. Armando Salles Oliveira, 201, 14404-600 Franca - SP, Brazil

Received: April 19, 2007; Revised: November 28, 2007

\begin{abstract}
$\mathrm{TiO}_{2}$ films have various applications, among them solar cells and photodegradation of pollutants. In this study, we investigated $\mathrm{TiO}_{2}$ films functionalized with the organic dye cyanidin extracted from black mulberry (Morus nigra). The $\mathrm{TiO}_{2}$ was functionalized by the sol-gel method and the film was deposited on glass substrates by dipcoating. Our aim was to investigate the interaction between the semiconductor and the dye, as well as the influence of the velocity and number of deposits on the characteristics of the film. Using ultraviolet-visible spectroscopy, we observed a shift from the maximum absorption band at $545 \mathrm{~nm}$ for the dye's ethanol solution to $595 \mathrm{~nm}$ for the film, indicating interaction of the cyanidin with the $\mathrm{TiO}_{2}$. The absorption spectra in the infrared region of the functionalized $\mathrm{TiO}_{2}$ particles showed bands characteristic of the oxide and indicated their interaction with the dye. Using profilometry and m-line techniques, we found that the films presented thicknesses in the order of $100 \mathrm{~nm}$. A SEM analysis confirmed the high density of the films.
\end{abstract}

Keywords: $\mathrm{TiO}_{2}$, films, cyanidin, sol-gel

\section{Introduction}

Porous $\mathrm{TiO}_{2}$ electrodes have various applications, among them solar cells and heterogeneous photoelectrocatalysis for the degradation of pollutants. In these devices, the structure of the oxide film deposited on transparent electrodes affects the energy conversion efficiency, for the size of the particles and pores interferes in the penetration of the electrolyte in solar cells and in the interaction with pollutant molecules in photocatalytic devices ${ }^{1-3}$.

Solar cells based on dye-sensitized $\mathrm{TiO}_{2}$ nanoparticles were first developed by Grätzel and coworkers ${ }^{4}$. Regenerative photoelectrochemical cells are composed of nanocrystalline $\mathrm{TiO}_{2}$ films sensitized with a dye. Under a light beam, the dye absorbs photons and injects electrons into the semiconductor's conduction band. The charge carriers then scatter to the external circuit. The dye is reduced by a redox pair, which, in turn, is also regenerated in the counter electrode ${ }^{1-4}$.

The use of natural products such as organic dyes in solar cells offers promising prospects for the advance of this technology, since photoexcitable dyes are substances that cede electrons easily, while the use of synthetic dyes involves several problems, such as their synthesis, purification and use, as well as the fact that they require rare metals ${ }^{5-8}$. Cyanidin is an organic dye of the flavonoid class found in leaves and fruits and responsible for the colors of various vegetal tissues, which has been studied for application as a sensitizer of this type of solar cell ${ }^{7-11}$ (Figure 1).

In most of these solar energy conversion devices, the $\mathrm{TiO}_{2}$ film is obtained by deposition of a colloidal suspension of commercial oxide particles (usually Degusa ${ }^{\circledR}$ ), but the development of nanocrystalline films with large and porous surface areas has increased the efficiency of these devices. In this context, the sol-gel process has proved to be a viable alternative to produce these films, since it is a simple and versatile method for the production of oxide nanoparticles of controlled sizes. The conventional method uses the hydrolytic route, which involves the initial hydrolysis of the alkoxide precursor followed by continual condensations between the hydrolyzed particles forming the gel. The reactions are:

Hydrolysis

$$
\begin{aligned}
& \equiv \mathrm{Ti}-\mathrm{OR}+\mathrm{H}_{2} \mathrm{O} \rightarrow \equiv \mathrm{Ti}-\mathrm{OH}+\mathrm{ROH} \\
& \text { Condensation } \\
& \equiv \mathrm{Ti}-\mathrm{OH}+\mathrm{HO}-\mathrm{Ti} \equiv \rightarrow \equiv \mathrm{Ti}-\mathrm{O}-\mathrm{Ti} \equiv+\mathrm{H}_{2} \mathrm{O} \text { (dehydration) } \\
& \equiv \mathrm{Ti}-\mathrm{OR}+\mathrm{HO}-\mathrm{Ti} \equiv \rightarrow \equiv \mathrm{Ti}-\mathrm{O}-\mathrm{Ti} \equiv+\mathrm{ROH} \text { (dealcoholation) }
\end{aligned}
$$

This process is carried out at room temperature, and the desired morphological properties of the particles are obtained by controlling the conditions under which the synthesis is carried out. Moreover, these materials are easily produced in film form. However, their disadvantages are the high cost of raw materials and considerable contraction in the process ${ }^{12-15}$.

The dip-coating technique, which consists of immersing a substrate in the sol at a controlled speed, has been used successfully to deposit oxide in the form of a thin film. This technique allows one not only to control the speed but also to vary the number of depositions, thereby obtaining films with controlled thicknesses ${ }^{12}$.

In this paper, we report on the preparation of $\mathrm{TiO}_{2}$ films functionalized with cyanidin from black mulberry (Morus nigra), using the hydrolytic sol-gel process to obtain the oxide and the dip-coating technique to deposit the films on glass substrates, with controlled speed and number of depositions. The interaction of the dye and the oxide was examined by UV-Vis spectroscopy and FTIR. The thermal stability of the hybrid organic-inorganic xerogel formed here was studied by thermal analysis. Surface area and pore volume were determined by nitrogen adsorption. Using profilometry and $\mathrm{m}$-line techniques, we were able to ascertain that the deposited films showed thicknesses in the order of $100 \mathrm{~nm}$. The micrographs obtained by scanning electron microscopy (SEM) revealed the high density 


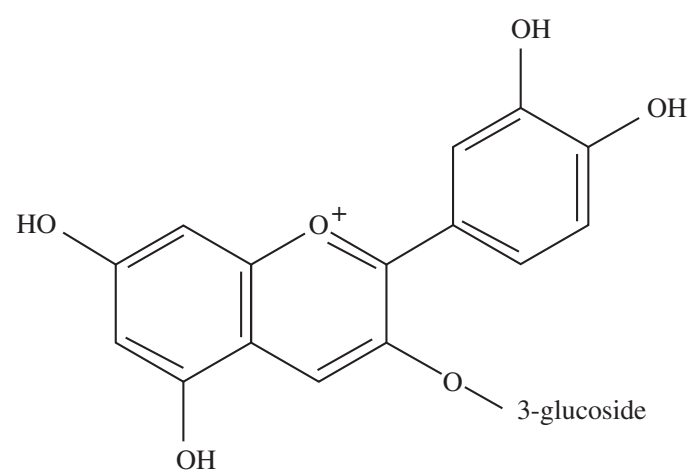

Figure 1. Molecular structure of the cyanidin.

of the films. Titanium dioxide was chosen and the semiconductor material, since it is a low-cost, abundant, and chemically inert material whose properties have already been studied. Because $\mathrm{TiO}_{2}$ is white and therefore does not absorb visible light, it is the cyanidin from mulberry that determines the absorption of light and the spectral response of the semiconductor.

\section{Experimental}

The titanium oxide was prepared by the hydrolytic sol-gel method, while the cyanidin solution was obtained from mulberries by macerating $1 \mathrm{~g}$ of the fruit with $12 \mathrm{~mL}$ of ethanol and filtering the resulting product. The titanium oxide sol functionalized with raw mulberry (Morus nigra) cyanidin extract was prepared by mixing $12 \mathrm{~mL}$ of ethanolic solution of dye, $1 \mathrm{~mL}$ of acetic acid as a stabilizing agent and $1 \mathrm{~mL}$ of titanium (IV) isopropoxide. The resulting blue sol was stirred for 30 minutes at $25^{\circ} \mathrm{C}$. The flowchart in Figure 2 illustrates the experimental procedure.

The sol-gel method was utilized to synthesize $\mathrm{TiO}_{2}$ because it is carried out at a low temperature, resulting in small particles with a high surface area and a large quantity of superficial Ti-OH groups due to incomplete condensation. Mulberries were used as a dye source because they contain large quantities of cyanidin ${ }^{11}$.

Deposition of the films was carried out by the dip-coating method using an controller model MQCT 2000-MP microprocessor-controlled syringe pump to deposit the films on glass substrate. The substrates were immersed in the sol at speeds of 50,70 and $100 \mathrm{~mm} / \mathrm{min}$, varying the number of immersions in the sol from 1 to 5 times to obtain films with different thicknesses.

The material left behind by deposition of the films was dried in the form of xerogel for subsequent FTIR, thermal and morphological characterization.

\section{Results and Discussion}

The absorption spectra in the ultraviolet-visible region were obtained using a HP 8452A diode array spectrophotometer. The cyanidin ethanol solution presented maximum absorption at 545 $\mathrm{nm}$, while the cyanidin-functionalized $\mathrm{TiO}_{2}$ sol showed maximum absorption at $590 \mathrm{~nm}$ and the films at $595 \mathrm{~nm}$. The shift to the infrared region at the absorption maxima of the sol and the functionalized film confirmed the reaction between the $\mathrm{TiO}_{2}$ and the mulberry cyanidin extract, since the interaction caused a reduction of the electron density in the chromophore group, thus reducing its polarity (bathochromic effect). Figure 3 illustrates the absorption spectra in the UV-visible region.

The surface area and porosity of the $\mathrm{TiO}_{2}$ and cyanidinfunctionalized $\mathrm{TiO}_{2}$ xerogel were determined by nitrogen adsorption-

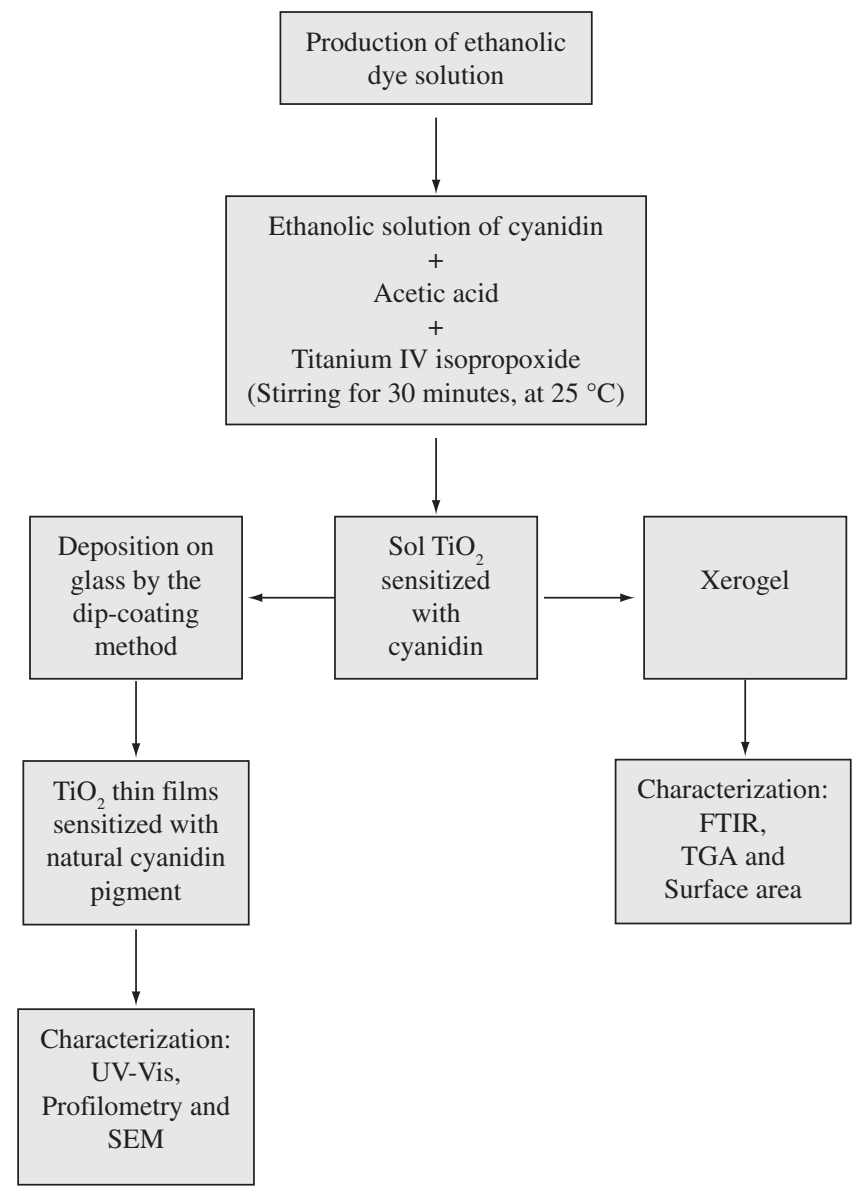

Figure 2. Flowchart of the experimental procedure.

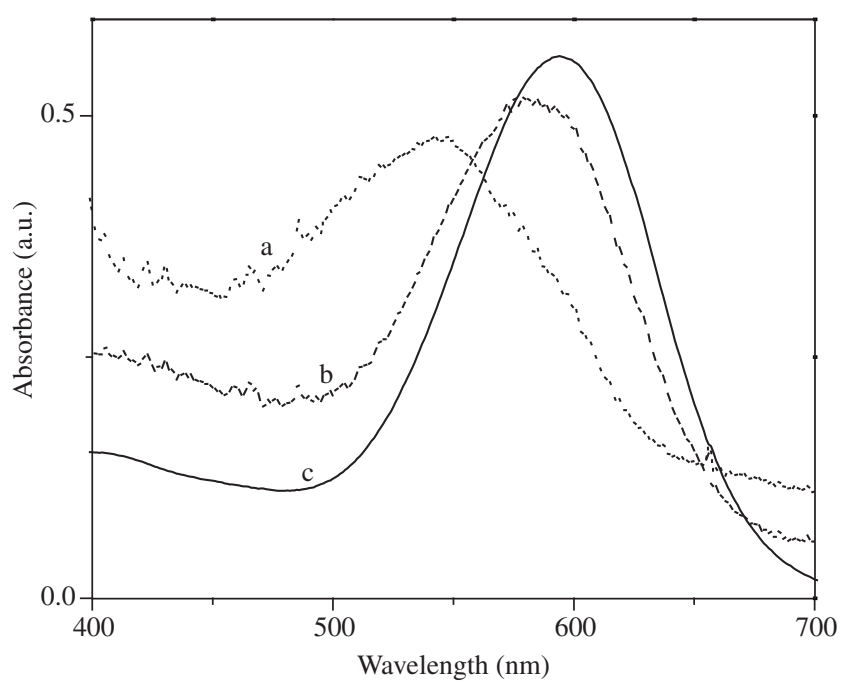

Figure 3. Absorption spectra: a) cyanidin ethanol solution; b) cyanidinfunctionalized $\mathrm{TiO}_{2}$ sol; and c) cyanidin-functionalized $\mathrm{TiO}_{2}$ film.

desorption isotherms in a Micromeritics ASAP 2020 Surface Area and Porosity Analyzer. The $\mathrm{TiO}_{2}$ xerogel showed a BET surface area of $202.9 \mathrm{~m}^{2} \cdot \mathrm{g}^{-1}$, a total pore volume of $0.105 \mathrm{~cm}^{3} \cdot \mathrm{g}^{-1}$, and an average pore size of $20.7 \AA$, while these values for the cyanidinfunctionalized hybrid material were $0.4733 \mathrm{~m}^{2} \cdot \mathrm{g}^{-1}, 0.000578 \mathrm{~cm}^{3} \cdot \mathrm{g}^{-1}$ 
and $48.9 \AA$, respectively. Because these measures are based on the adsorption and desorption of nitrogen by $\mathrm{OH}$ groups at the surface of $\mathrm{TiO}_{2}$ particles, the measures will show incorrect values if the $\mathrm{OH}$ groups are linked to a molecule, preventing them from interacting with the nitrogen. The alterations in the values of surface area and porosity are attributed to the efficiency of the dye's adsorption by the $\mathrm{TiO}_{2}$ particles. In a study of $\mathrm{TiO}_{2} \mathrm{R}-213$ produced by a chemical company, Agnieszka ${ }^{16}$ reported values of $39.9 \mathrm{~m}^{2} \cdot \mathrm{g}^{-1}, 0.0981 \mathrm{~cm}^{3} \cdot \mathrm{g}^{-1}$ and $98.4 \AA$ for BET surface area, total pore volume and average pore size, respectively. The larger surface area of the $\mathrm{TiO}_{2}$ material presented here was probably due to incomplete condensation of $\mathrm{Ti}-\mathrm{OH}$ groups and low particle sizes characteristic of materials obtained by the sol-gel process, which allowed for the adsorption of a larger amount of dye per $\mathrm{TiO}_{2}$ mass. Dye- $\mathrm{TiO}_{2}$ interactions were confirmed by a shift of Ti-O surface vibration in the FTIR analysis. The conventional methods of solar cell film production require a thick $\mathrm{TiO}_{2}$ layer ( 1 to $10 \mu \mathrm{m}$ ) so that a sufficient quantity of dye is adsorbed to allow for the absorption of a significant fraction of the incident light ${ }^{17}$. Our films, whose thickness was in the order of 100 $\mathrm{nm}$, presented light absorption in the same order of magnitude as 4 $\mu \mathrm{m}$ thick films produced by the conventional method.

The infrared absorption spectra of the xerogels were obtained with a Perkin Elmer FTIR 1600 infrared spectrophotometer, operating from 400 to $4000 \mathrm{~cm}^{-1}$ using $\mathrm{KBr}$ tablets. The absorption spectra in the infrared region of the $\mathrm{TiO}_{2}$ xerogel and of the cyanidinfunctionalized oxide presented bands characteristic of $\mathrm{TiO}_{2}$, with the bands at 550 and $655 \mathrm{~cm}^{-1}$ attributed to normal $\mathrm{TiO}_{2}$ stretching. The bands in the regions of 1030, 1425 and $1542 \mathrm{~cm}^{-1}$ observed for non-sensitized $\mathrm{TiO}_{2}$, were attributed to stretching and vibrations of the $\mathrm{Ti}-\mathrm{O}-\mathrm{Ti}$ group, indicating the formation of the inorganic matrix ${ }^{18-20}$. The band at $1425 \mathrm{~cm}^{-1}$ in the $\mathrm{TiO}_{2}$ spectrum shifted to 1445 $\mathrm{cm}^{-1}$ in the spectrum of the functionalized $\mathrm{TiO}_{2}$. The band ascribed to superficial $\mathrm{Ti}-\mathrm{O}$ vibrations appeared at $755 \mathrm{~cm}^{-1}$ for $\mathrm{TiO}_{2}$ and at $790 \mathrm{~cm}^{-1}$ in the cyanidin-functionalized oxide, indicating the oxide was functionalized by the dye ${ }^{18-20}$ (Figure 4).

The band at $3745 \mathrm{~cm}^{-1}$ in the $\mathrm{TiO}_{2}$-cyanidin spectrum was attributed to stretching of the $\mathrm{OH}$ groups of the glycoside and of the phenolic groups, confirming the presence of the dye in the material $^{20-23}$.

The TGA curves and the curves of the $\mathrm{TiO}_{2}$ and cyanidinfunctionalized $\mathrm{TiO}_{2}$ xerogels were obtained with a SDT Q600

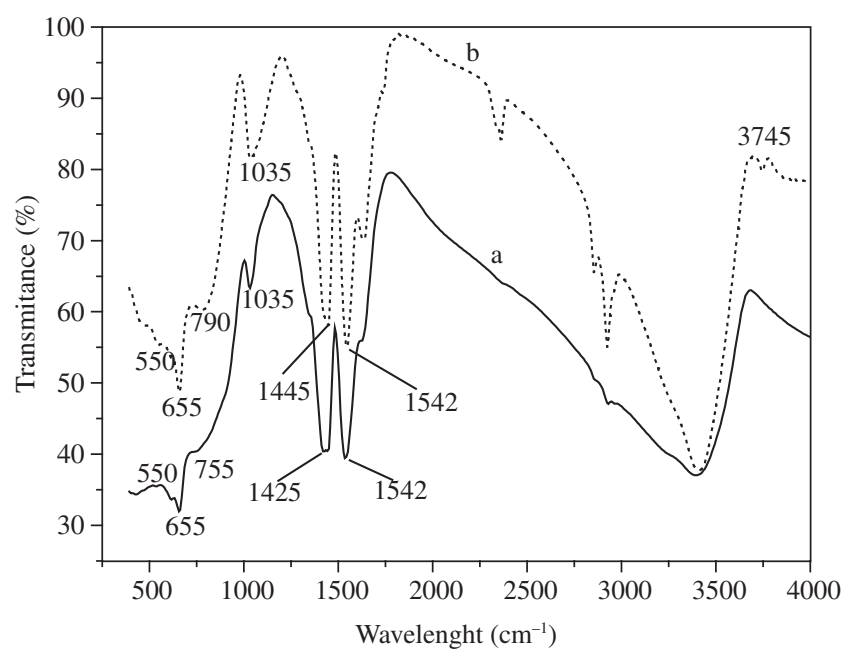

Figure 4. FT-IR spectra: a) $\mathrm{TiO}_{2}$; and b) cyanidin-functionalized $\mathrm{TiO}_{2}$.
Simultaneous DTA-TG analyzer (TA Instruments) in a nitrogen atmosphere at a heating rate of $20^{\circ} \mathrm{C} / \mathrm{min}$.

The samples showed rapid weight loss at around $100{ }^{\circ} \mathrm{C}$ resulting from the evaporation of residual solvent in the xerogel (powder), and another weight loss at around $340{ }^{\circ} \mathrm{C}$ corresponding to the decomposition of organic compounds such as acetic acid covalently bonded to $\mathrm{TiO}_{2}$. The DTG curve of cyanidin-functionalized $\mathrm{TiO}_{2}$ xerogel presented a peak at around $430{ }^{\circ} \mathrm{C}$, which was not present in the DTG curve of $\mathrm{TiO}_{2}$ xerogel and which can be attributed at cyanidin linked to $\mathrm{TiO}_{2}$ decomposition. These results led us to consider that the cyanidin, in this material, reaches thermal stability at around $400{ }^{\circ} \mathrm{C}$ (Figure 5 and 6).

The thickness of the films was determined by the profilometry technique, which indicated a thickness of about $100 \mathrm{~nm}$ as well as good homogeneity.

The SEM micrographs, obtained with a JEOL JSM T330A scanning electron microscope, revealed that the films were of high density and had a very homogeneous structure devoid of cracks, as indicated in Figure 7.

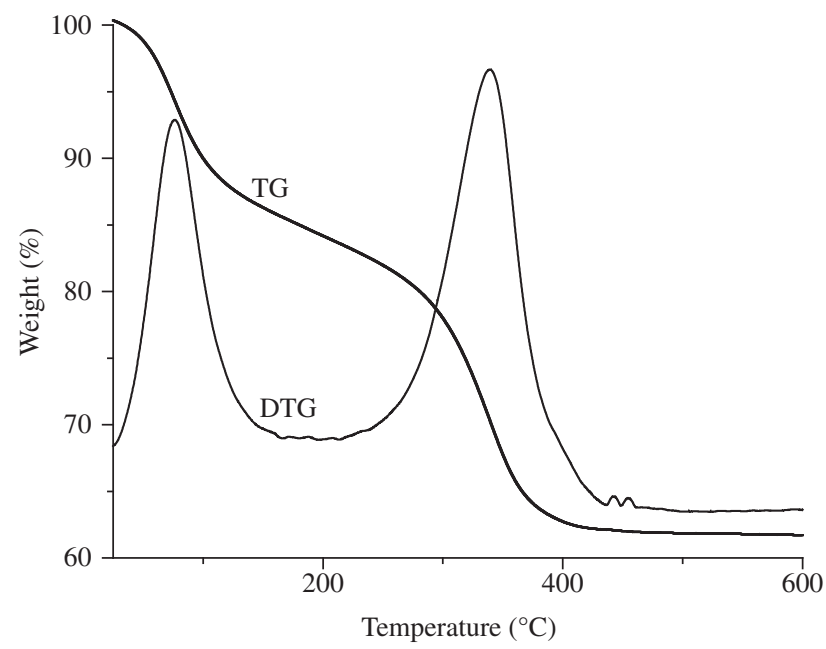

Figure 5. TG curve and DTG of $\mathrm{TiO}_{2}$ powder.

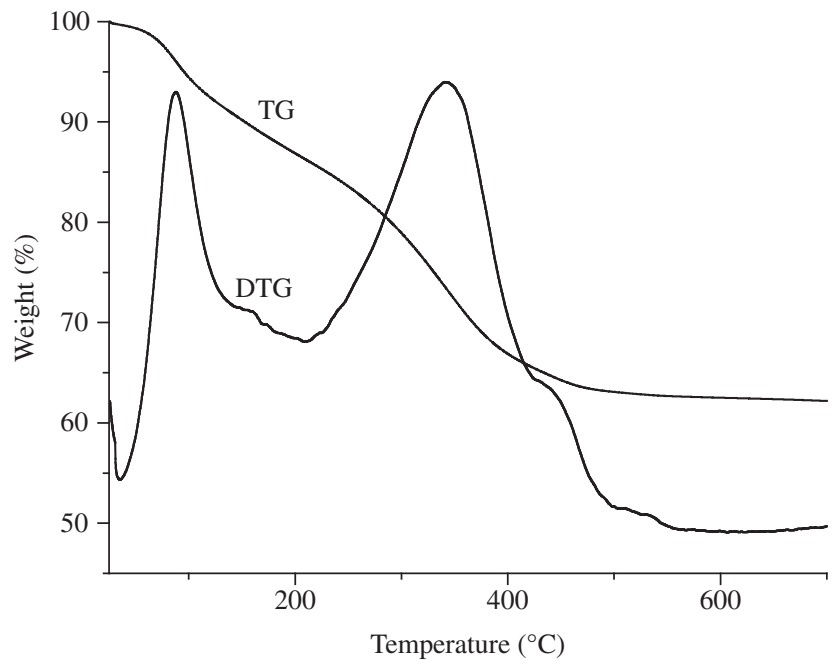

Figure 6. TG curve and DTG of cyanidin-functionalized $\mathrm{TiO}_{2}$ powder. 


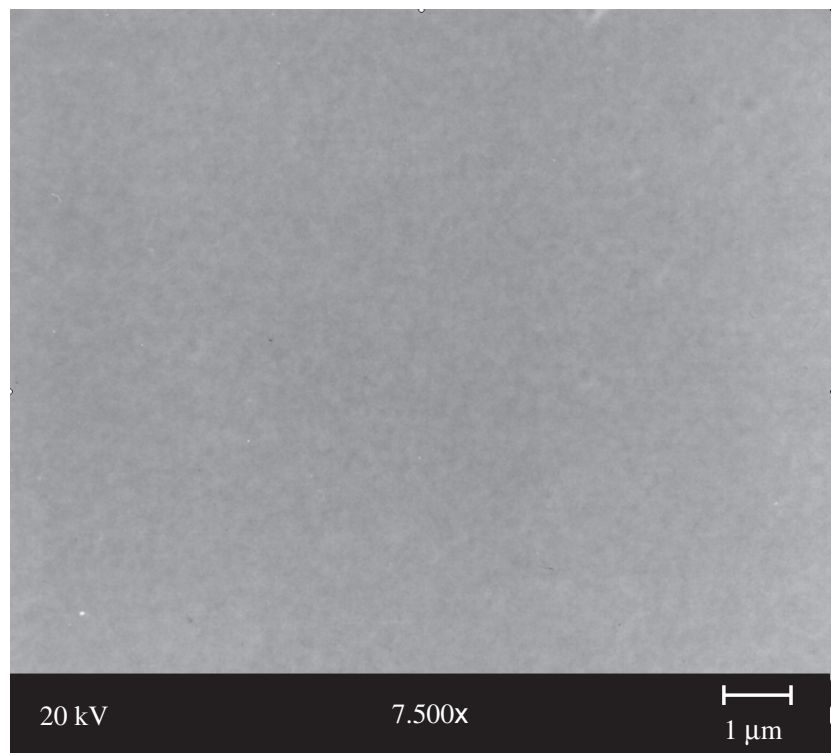

(a)

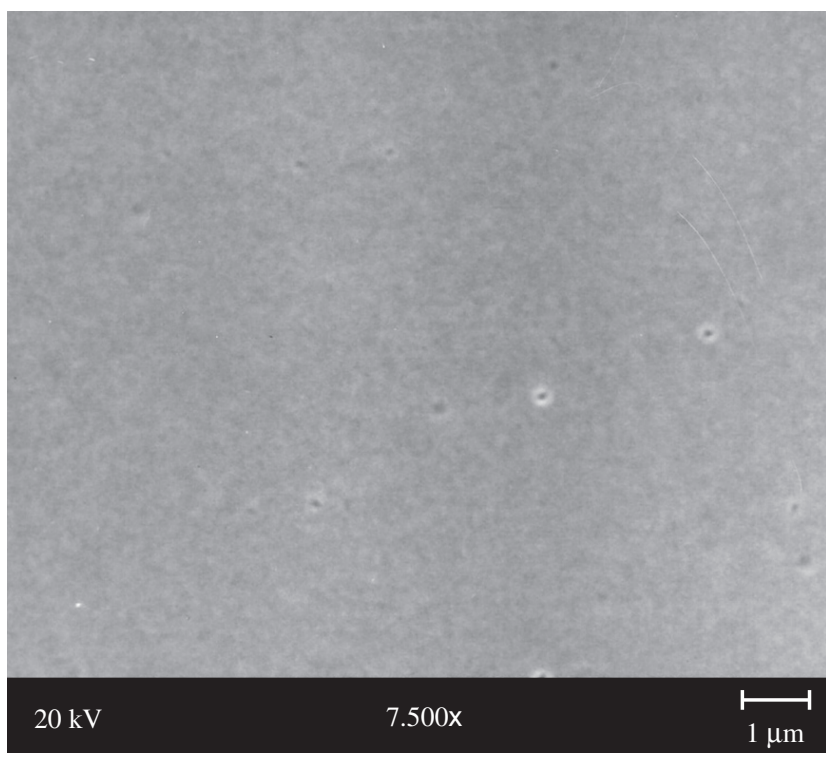

(b)

Figure 7. SEM micrograph of films: a) $70 \mathrm{~mm} / \mathrm{min} 3 \mathrm{dips}$; and b) $50 \mathrm{~mm} / \mathrm{min} 2 \mathrm{dips}$.

\section{Conclusions}

Unlike the systems studied previously, in which the interaction between cyanidin and $\mathrm{TiO}_{2}$ particles occurs after the particles or films have been obtained, in the present work this interaction occurred during the reactions of hydrolysis and condensation, resulting in a material with a larger quantity of adsorbed dye molecules in relation to the number of titanium atoms, possibly leading to the greater efficiency of solar cells obtained by this methodology.

The thin films were transparent, homogeneous, uniform, with a thickness in the order of $100 \mathrm{~nm}$, and presented excellent adhesion to the substrate. These characteristics indicate the possible application of these films in solar cells.

\section{References}

1. Falaras P, Goft AH, Bernard MC, Xagas A. Characterization by Resonance Raman Spectroscopy of sol-gel $\mathrm{TiO}_{2}$ films sensitized by the $\mathrm{Ru}\left(\mathrm{PPh}_{3}\right)_{2}(\mathrm{dcbipy}) \mathrm{Cl}_{2}$ complex for solar cells application. Solar Energy Materials \& Sollar Cells. 2000; 64(2):167-184.

2. Tennakone K, Kumarashinghe AR, Kumara GRRA, Wijayantha KGU, Sirimanne PM. Nanoporous $\mathrm{TiO}_{2}$ photoanode sensitized with the flower pigment cyaniding. Journal of Photochemistry and Photobiology. 1997; 108:193-195.

3. Agnaldo JS, Bastos JBV, Cressoni1 JC, Viswanathan, G.M. Células Solares de $\mathrm{TiO}_{2}$ sensibilizado por corante. Revista Brasileira de Ensino de Física. 2006; 28(1):77-84

4. 'Regan BO, Grätzel M. A low-cost, high-efficiency solar cell based on dye-sensitized colloidal $\mathrm{TiO}_{2}$ films. Nature. 1991; 353:737-740.

5. Gerfin T, Grätzel M. Molecular and supramolecular surface modification of nanocrystalline $\mathrm{TiO}_{2}$ films: charge-separating and charge-injecting devices. Progress in Inorganic Chemistry. 1997; 44:345-393.

6. Niyama E, Alencar AC, Vila LD, Stucchi EB, Davolos MR. Filmes delgados luminescentes obtidos a partir de hidroxicarbonetos de ítrio ativados por európio ou térbio. Química Nova. 2004; 27(2):183-187.

7. Nozik AJ. Quantum dot solar cells. Physica E: Low-dimensional Systems and Nanostructures. 2002; 14:115-120.
8. Cherepy NJ, Smestad GP, Gratzel M, Zhang JZ. J. Phys. Chem. Ultrafast Electron Injection: Implications for a Photoelectrochemical Cell Utilizing an Anthocyanin Dye-Sensitized $\mathrm{TiO}_{2}$ Nanocrystalline Electrode. Journal of Physical Chemistry B. 1997; 101:9342-9351.

9. Smestad GP, Gratzel, M. Demonstrating Electron Transfer and Nanotechnology: A Natural Dye-Sensitized Nanocrystalline Energy Converter. J. Chem. Education. 1998; 75(6):752-756.

10. Hinsch A, Kroon JM, Kern R, Uhlendorf I, Holzbock J, Meyer A, Ferber J. Long-term stability of dye-sensitised solar cells. Prog. Photovoltaics. 2001; 9(1):425-438.

11. Malacrida CR, da Motta S. Antocianinas de suco de uva: composição e estabilidade. B. CEPPA. 2006; 24(1):59-82.

12. Nassar EJ, Ciuffi KJ, Gonçalves RR, Messaddeq Y, Ribeiro SJL. Filmes de Titânio-Silício preparados por "spin" e "dip-coating". Química Nova. 2003; 26(5):674-677.

13. Li X, Xiong Y, Li Z, Xie Y. Large Scale Fabrication of $\mathrm{TiO}_{2}$ Hierarchical Hollow Spheres. Inorganic Chemistry. 2006; 45(9):3943-3495.

14. Corriu RJP. The Control of Nanostructured Solids: A Challenge for Molecular Chemistry. Eur. J. Inorganic Chemistry. 2001; 5:1109-1121.

15. Sanchez C, Julian B, Belleville P, Popall M. Applications of hybrid organic-inorganic nanocomposites. J. Materials. Chemistry. 2005; 15:3559-3592.

16. Andrzejewska A, Krysztafkiewicz A, Jesionowski T. Adsorption of organic dyes on the aminosilane modified $\mathrm{TiO}_{2}$ surface. Dyes and Pigments. 2004; 62(2):121-130.

17. Ehret A, Stuhl L, Spitler MT. Spectral Sensitization of $\mathrm{TiO}_{2}$ Nanocrystalline Electrodes with Aggregated Cyanine Dyes. J. Phys. Chem. 2001; 105:9960-9965.

18. González MB, Wu A, Vilarinho PM. Influence of Solvents on the Microstructure and Dieletric Properties of $\mathrm{Ba}_{0.5} \mathrm{Sr}_{0.5} \mathrm{TiO}_{3}$ Thin Films Prepared by a Diol-Based Sol-Gel Process. Chem. Mater. 2006; 18:1737-1744.

19. Kontos AI, Arabatzis IM, Tsoukleris DS, Kontos AG, Bernard MC, Petrakis DE, Falaras P. Efficient photocatalysts by hydrothermal treatment of $\mathrm{TiO}_{2}$. Catalysis Today. 2005; 101(3-4):275-281.

20. Maira AJ, Coronado JM, Augugliaro V, Yeung YKL, Conesa ZJC, Soria J. Gas-phase photo-oxidation of toluene using nanometer-size $\mathrm{TiO}_{2}$ catalysts. Journal of Catalysis. 2001; 202(2):413-420. 
21. Dangles O, Norio S, Brouillard R. Kinetic and Thermodynamic Control of Flavylium Hydration in the Pelargonidin-Cinnamic Acid Complexation. Origin of the Extraordinary Flower Color Diversity of Pharbitis nil. J. Am. Chem. Soc. 1993; 115:3125-3132.

22. Marković DJM, Baranac JM, Brdarić TP. Electronic and infrared vibrational analysis of cyanidin-quercetin copigment complex. Spectro- chimica Acta Part A: Molecular and Biomolecular Spectroscopy. 2005; 62(1-3):673-680

23. Souza RFV, Giovani WF. Antioxidant properties of complexes of flavonoids with metal ions. Redox Report. 2004; 9(2):97-104. 